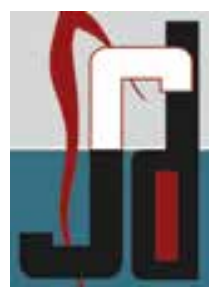

CASE REPORT

\title{
Peripheral Cemento-Ossifying Fibroma of Maxilla
}

\author{
A.Aroumougam ${ }^{1}$, N.Vezhavendhan ${ }^{2}$, Suganya.R $^{3}$, Umamaheswari.G $^{4}$
}

ABSTRACT : Peripheral Cement- Ossifying Fibroma $[\mathrm{PCOF}]$ is a reactive gingival growth mostly occurring in the anterior region of the maxilla, predominantly seen in teenagers and young adults. Here we report a case of PCOF in a 42 years old female patient presents with the history of asymptomatic gingival growth in right maxillary premolar region over a period of 6 months. Histopathological examination was suggestive of Peripheral cement- ossifying fibroma which exhibits the presence of cellular connective tissue stroma with focal calcifications. To prevent recurrence an early diagnosis and surgical excision is required.

Keywords: Gingival growth, Peripheral cemento ossifying fibroma, recurrence

\section{Introduction :}

Ossifying fibroma is a benign tumor involving bone and gingiva in oral and maxillo-facial region. It mainly consists of proliferating fibroblasts with osseous structures that include bone and calcifications, these lesions are well circumscribed from the adjacent bone. The calcified structures present in this lesion might arise from periosteal cells or from the cells of periodontal ligament. Ossifying fibromas is of two types: the central type and the peripheral type. The central type, it arises from the endosteum or the periodontal ligament. The periodontal ligament which is present adjacent to the root apex and also it causes medullar cavity expansion. ${ }^{[1]}$ The peripheral type, mainly occurs in the soft tissues bearing areas of tooth and jaws. Most frequently it occurs on gingival and accounts for about $3.1 \%{ }^{[2]}$ of all oral tumors and for $9.6 \%$ of gingival lesions. ${ }^{[3]}$

The pathogenesis of this lesion is uncertain. Since they have clinical and histopathological similarities, some peripheral cemento-ossifying fibromas are believed to develop initially as a pyogenic granuloma that undergoes fibrous maturation and subsequent calcification. It is usually associated with local irritants such as calculus, bacterial plaque, orthodontic appliances, ill-adapted crowns and irregular restorations. ${ }^{[4]}$

\section{Case Report}

A 42 year old female reported with a slow growing asymptomatic growth on the bicuspid region in between maxillary first and second right premolars since 6 months. Her past medical history was non- contributory and no significant finding evident on extraoral examination. Intraoral examination revealed a well-circumcised, sessile growth in between 14 and 15 , measuring about $2.5 \times 3 \mathrm{~cm}$ in diameter and the growth in the gingiva extends from the buccal to the palatal aspect involving the interdental papilla [Figure-1]. It was firm in consistency and non-tender. Overlying mucosa appeared to be lobulated and the surface is smooth with few erythematous regions. She had generalized sub gingival and supra gingival calculus deposits. Based on the clinical findings, it was provisionally diagnosed as the mature pyogenic granuloma. The lesion was excised under local anesthesia and sent for histopathological examination. The radiographic image of excised specimen revealed mixed radiolucency with scattered radiopacities. Macroscopic examination of the excised specimen revealed a smooth lobulated tissue with evidence of scattered calcified structures. On sectioning gritty sensation was felt [Figure-2]. Histopathological examination of the lesion revealed spicules calcified tissue in the trabecular pattern and small spherical spherules resembling cementum in the myxomatous background. The overlying epithelium is stratified squamous parakeratinized and is of varying thickness ranging from atrophic to hyperplastic in nature. Some of the areas of the epithelium are ulcerated and focal areas in the connective tissue stroma exhibit inflammatory cells predominantly of lymphocytes [Figure- $\mathbf{3 a} \mathbf{\&} \mathbf{3 b}$ ]. Based on the findings a final diagnosis of Peripheral cemento ossifying fibroma was made. A six month post-surgical follow-up showed no evidence of recurrence. 


\section{Discussion :}

Peripheral cemento-ossifying fibroma is a benign gingival growth and it is thought to be either reactive or neoplasm. It accounts for $3.1 \%$ of all oral tumors and $9.6 \%$ of all gingival lesions. Mostly occurs in young adults and adolescents, and predominantly seen in females, due to hormonal influences, within the peak age range of 10-19 years. ${ }^{[5]}$ It usually occurs in the second decade and its incidence declines after the third decade, which was contradictory in our case, as the patient was aged 42 years at the time of reporting. Bhasin et al., ${ }^{[6]}$ and Mohiuddin et al reported few cases in elderly patients. ${ }^{[7]}$ Mostly it is reported to occur in the interdental papilla of the maxillary incisor-canine region, ${ }^{[5]}$ whereas, in the present case, the lesion was observed in the interdental papilla of the right maxillary first and second premolar region, which is a less common site. However, similar cases with lesions in the maxillary region have been reported by Ashok et al. ${ }^{[8]}$ and Pereira et al. ${ }^{[9]}$

WHO classified cemento-ossifying fibroma as an osteogenic neoplasm of fibro-osseous group. Mutations in the tumor suppressor gene HRPT2 was proposed for intra osseous type and peripheral cemento-ossifying fibroma most frequently associated with the local irritant such as calculus, bacterial plaque, orthodontic appliances, ill-adapted crowns and irregular restorations and also due to hormonal disturbances. Even though its origin is uncertain, it is thought to originate from cells of the periodontal ligament due to the following reasons: Unique occurrence in the gingiva (interdental papilla), because of the proximity of the gingiva to the periodontal ligament and the presence of oxytalin fibers within the mineralized matrix of some lesions. ${ }^{[10]}$ In this particular case, it is assumed that local irritants such as plaque and calculus played a vital role in the pathogenesis of the lesion. The central variant of the ossifying fibroma were also identified in patients, who presents with a rare condition of hyperparathyroidism jaw tumor syndrome. This condition is characterized by thyroid adenoma or carcinoma, ossifying fibromas of the jaws, renal cysts and Wilm's tumor. ${ }^{[1]}$

PCOF clinically appears as a lesion with sessile or a pedunculated base, which usually arises in the interdental papilla. Usually, it measures less than 2 $\mathrm{cm}$ in diameter, but some lesions are larger than 10 $\mathrm{cm}$, occasionally observed. The tumor occurs both in the maxilla and mandible and more than $80 \%$ of all lesions occurred in the region anterior to the molar. The probability of tooth migration due to the presence of PCOF has been reported. ${ }^{[4]}$ PCOF can show diffuse radiopaque calcifications, but not all lesions exhibit these radiographic characteristics. Most lesions are not associated with bone destruction. Following lesions such as pyogenic granuloma, peripheral giant cell granuloma, and peripheral odontogenic fibroma was considered as the differential diagnosis.

Histopathologically, PCOF shows either an intact or ulcerated stratified squamous epithelium and is seen overlying the highly cellular connective tissue stroma, comprising of fibroblasts, with areas of calcification, which may consist of bone, cementum-like material, dystrophic calcification or a combination of all these. Cementum like material noticed could be an altered bone and mineralized areas could be a dystrophic calcification or metaplasia of the connective tissue fibroblast to form calcification. The term cementoossifying fibroma is thought to be inappropriate, because clinical and histopathological similar lesions were also noticed in skull, femur, and tibia and support the fact that the cementum like material are bone. And it is also proposed that the basophilic bone particles found within the lesion called cementicles, basically not derived from the cementum but instead represent a dysmorphic product of this tumor similar to the keratin pearls seen in the squamous cell carcinoma. ${ }^{[5]}$

The management consists of an elimination of the associated irritating factors, oral prophylaxis, and total surgical excision, along with the involved periosteum, to minimize the possibility of recurrence, as it has a high recurrence rate of approximately $8-20 \%$. Hence, long-term postoperative follow-up is also essential. ${ }^{[5]}$ The patient reported here is on periodic postoperative follow-up since six months and has shown no recurrence till the date of reporting.

\section{Conclusion :}

PCOF is a slow progressive lesion with limited growth. Many cases will progress for long periods before the patient seeks treatment because of lack of symptoms associated with the lesion. There is possible to misdiagnose PCOF from other reactive lesions arising from the gingiva. Therefore, histopathological examination is essential for an accurate diagnosis and 


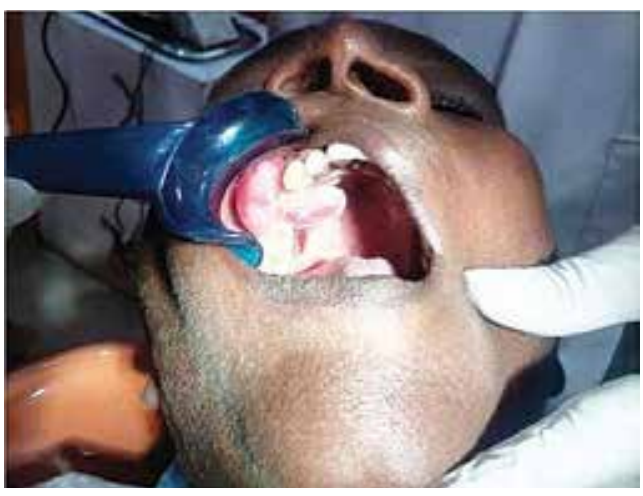

Figure-1: Photograph showing gingival growth extending from buccal to palatal aspect of 14 \&15

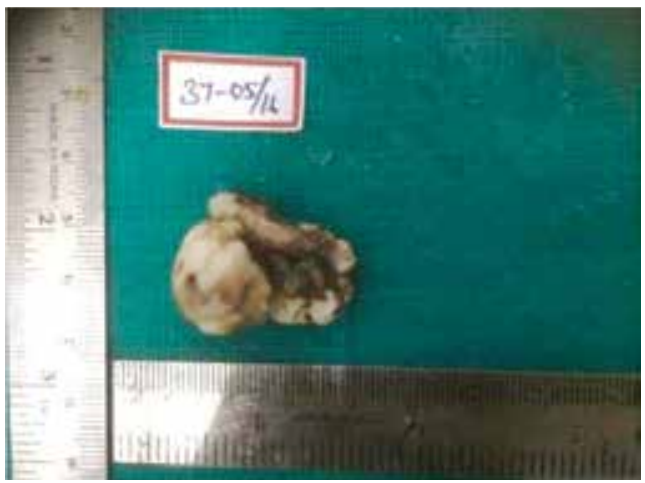

Figure-2: Photograph showing macroscopic feature of excised specimen

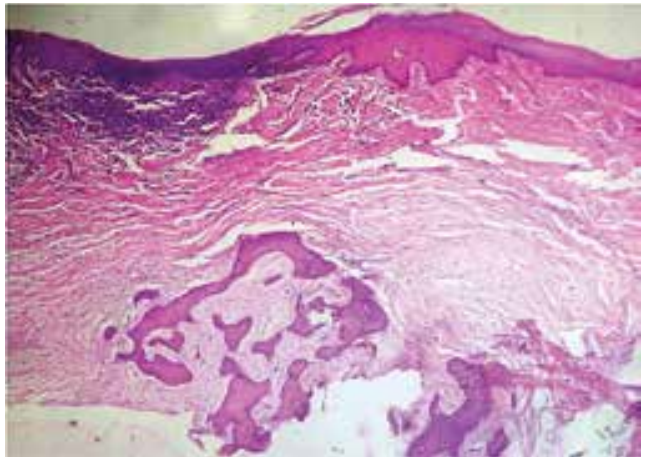

Figure-3a: Photomicrography showing stratified squamous parakeratinized epithelium and calcified material in the connective tissue (H \& E- 4X)

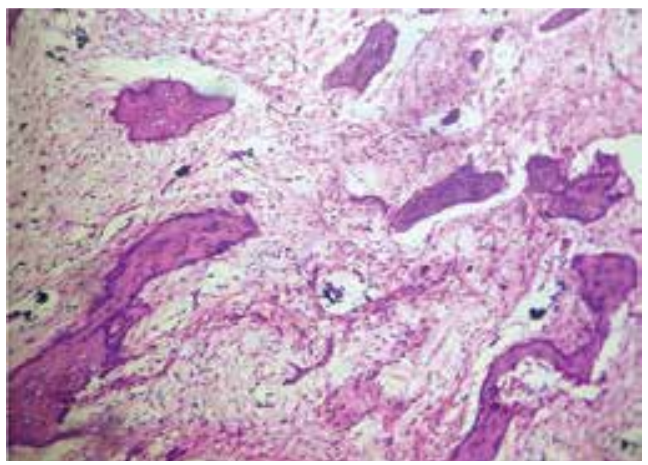

Figure- 3b: Photomicrography showing spicules of calcified tissue in the trabecular pattern and small spherical spherules resembling cementum in the myxomatous background (H \& E- 10X) for proper management. Incomplete surgical removal along with the presence of local irritating factors will cause recurrence. Complete excision with aggressive curettage of the adjacent tissues is essential to prevent recurrence. Post-operative follow - up is required because of the growth potential and $8-20 \%$ recurrence rate.

\section{References :}

1. Chatterjee A, Ajmera N, Singh A. Peripheral cementoossifying fibroma of maxilla. Journal of Indian Society of Periodontology. 2010;14 (3): 186- 189.

2. Kenney JN, Kaugars GE, Abbey LM. Comparison between the peripheral ossifying fibroma and peripheral odontogenic fibroma. J Oral Maxillofac Surg 1989;47:378-82.

3. Walters JD, Will JK, Hatfield RD, Cacchillo DA, Raabe DA. Excision and repair of the peripheral ossifying fibroma: a report of 3 cases. J Periodontol 2001;72:939

4. Delbem A, Cunha R, Silva J, Soubhia A. Peripheral cementoossifying fibroma in child. a follow-up of 4 years. report of a case. Eur J Dent 2008;2:134-7.

5. Verma E, Chakki AB, Nagaral SC, Ganji KK. Peripheral cementoossifying fibroma: the Case series literature review. Case Rep Dent 2013;2013:930870.

6. Bhasin M, Bhasin V, Bhasin A. Peripheral ossifying fibroma. Case Rep Dent 2013;2013:497234.

7. Mohiuddin K, Priya NS, Ravindra S, Murthy S. Peripheral ossifying fibroma. J Indian Soc Periodontol 2013;17:507-9.

8. Ashok S, Gupta AA, Ashok KP, Mhaske SA. Peripheral ossifying fibroma: A rare case affecting the maxillary region. Indian J Dent 2016;7:141-3.

9. Pereira T, Shetty S, Shetty A, Pereira S. Recurrent peripheral cemento-ossifying fibroma. J Indian Soc Periodontol 2015;19:333-5.

10. Sinha S, Reddy Enja SP, Chandra S, Nethan S. Peripheral cemento-ossifying fibroma: Report of a case in an elderly patient. J Indian Acad Oral Med Radiol 2014;26:204-8.

11. Neville BW, Damm DD, Allen CM, Bouquot J. Oral and maxillofacial pathology. 3rd ed. St. Louis, Missouri: Saunders Elsevier; 2009. p. 521-2. 


\section{Address of Correspondence}

Dr. A. Aroumougam

Post Graduate Student

Indira Gandhi Institute of Dental Sciences

Sri Balaji Vidhyapeeth University

Pondicherry - India.

Cell : 9443178721

Email id: arou_maha@yahoo.co.in

\section{Authors:}

${ }^{1}$ Post Graduate Student, Indira Gandhi Institute of Dental Sciences

Sri Balaji Vidhyapeeth University

${ }^{2}$ Professor, Department of Oral Pathology \& Microbiology, Indira Gandhi Institute of Dental Sciences, Sri Balaji Vidyapeeth University, Pondicherry

${ }^{3}$ Senior lecturer, Department of Oral Pathology and Microbiology Indira Gandhi Institute of Dental Sciences, Sri Balaji Vidhyapeeth University, Pondicherry.

${ }^{4}$ Post graduate student, Department of Oral Pathology and Microbiology, Indira Gandhi Institute of Dental Sciences Sri Balaji Vidhyapeeth University, Pondicherry.

\section{How to cite this article :}

A.Aroumougam, N.Vezhavendhan, Suganya.R, Umamaheswari.G. Peripheral Cemento-Ossifying Fibroma of Maxilla. Journal of Scientific Dentistry, 2017;7(1):28-31

Source of Support : Nil, Conflicts of Interest : None declared 